\title{
Parental feeding responses to experimental short-term partner removal in a species with male and female brood desertion
}

\author{
Alejandro Cantarero ${ }^{1,2,3}$ [D $\cdot$ Mireia Plaza ${ }^{2} \cdot$ Juan Moreno $^{2} \cdot$ M. Griggio $^{3}$ \\ Received: 28 December 2018 / Revised: 29 April 2019 / Accepted: 8 May 2019 / Published online: 20 May 2019 \\ (C) The Author(s) 2019
}

\begin{abstract}
As parental care is costly, it can be expected that there will be a sexual conflict between parents over the individual levels of parental investment because each parent has limited resources to invest in a reproductive event. Theoretical models of parental investment predict that when one parent reduces its parental effort, the other parent should adjust its effort facultatively to compensate for the decrease in the mate's contribution. Here, we tested for facultative adjustments in care in the rock sparrow, Petronia petronia. In this species, both sexes can desert the brood, creating the potential for strong sexual conflict over parental care to occur. To that end, we examined how rock sparrow parents adjust their level of care in response to an experimental mate removal for a limited time period, mimicking the starting phase of the desertion process. We compared male and female provisioning rates before and after an experimental mate removal. Males behaved according to the prediction of compensatory adjustment, as they allocated more care to the offspring and returned faster to the nest after female removal, whereas females showed no response. Our study shows sexual differences in response to mate removal in a species with biparental care and strong sexual conflict over parental care, and suggests that males may use the female absence to determine their actual parental effort.
\end{abstract}

\section{Significance statement}

Strong differences in parental care, with one sex providing more care than the other, are widespread across the animal kingdom. Theoretical models of parental investment predict that when one parent reduces its care, the mate should adjust its care facultatively to compensate. Here, we tested for facultative adjustments in care in the rock sparrow when their mates were experimentally removed for a limited time period. We show that only male behavior was consistent with theoretical predictions as they increased their frequency of provisioning significantly after mate removal, whereas females showed no response. Our study suggests that members of a pair do not make independent decisions, but negotiate to modify their effort in direct response to the prior effort of their mate.

Keywords Compensation $\cdot$ Mate removal $\cdot$ Negotiation $\cdot$ Petronia petronia $\cdot$ Rock sparrow $\cdot$ Sexual conflict

Communicated by J. A. Graves

Alejandro Cantarero alex.cantarero@hotmail.com

M. Griggio matteo.griggio@unipd.it

1 Department of Biology, University of Turku, 20014 Turku, Finland

2 Departamento de Ecología Evolutiva, Museo Nacional de Ciencias Naturales - CSIC, C/ José Gutiérrez Abascal 2, 28006 Madrid, Spain

3 Dipartimento di Biologia, Università di Padova, Via U. Bassi 58/B, I-35131 Padova, Italy

\section{Introduction}

Avian reproductive biology encompasses different patterns of parental care (reviewed by Clutton-Brock 1991; see also Birkhead 1999; Wesołowski 2004). In about $81 \%$ of species, both parents share parental care (biparental care), while other species exhibit unisexual parental care for the offspring, whereby care is carried out by either the male or the female (e.g., Lack 1968; Cockburn 2006). Moreover, some species show variation in the patterns of parental care within a single population and throughout the breeding season (e.g., Persson and Öhrström 1989; Székely et al. 1996; Pilastro et al. 2003; Pierce et al. 2010). As parental care is costly, it can be expected that there will be a sexual conflict between parents over the 
individual levels of parental investment (Trivers 1972). Thus, biparental care has served as an ideal model system in answering evolutionary ecology questions, particularly those related to the conflict between two unrelated individuals (McNamara et al. 1999; Royle et al. 2002; Smiseth and Moore 2004). In species where males and females cooperate to raise the young, a reduction in parental effort by one mate may result in different strategies by its partner, such as the maintenance of caring activities at the same level, the increase or decrease of its own effort, or the desertion of the offspring (Harrison et al. 2009). Increasing its level of care in response to a reduction in a mate's effort may imply costs in reduced survival prospects (Jönsson et al. 1998; Santos and Nakagawa 2012). On the other hand, increasing its effort may increase the fitness of the offspring being reared (reviewed by Székely et al. 1996; Barta et al. 2002; Harrison et al. 2009).

The payoffs for increasing, reducing, or maintaining the level of effort may be different for the two sexes (Szentirmai et al. 2007) and may also vary over the breeding season (Székely et al. 1999). After one mate has reduced its effort, the remaining parent has different options with regard to the effort it should invest in rearing its offspring (Sanz et al. 2000; Harrison et al. 2009; Lendvai et al. 2009). There are three general strategies for reacting to mate absence: (1) increasing efforts to compensate partially or fully for the loss of the mate (Leniowski and Wegrzyn 2018), (2) continuing to provide the same amount of care as before, regardless of the reduction in mate effort (reviewed in Osorno and Székely 2004), and (3) decreasing efforts, which includes complete brood desertion where fitness costs related to caring for offspring outweigh the benefits (Székely et al. 1996). Interestingly, a synergistic effect of biparental cooperation on offspring fitness which could favor the evolution of biparental cooperation has recently been demonstrated (Pilakouta et al. 2018). Moreover, some authors have presented models in which the young are better off when cared for by a single parent than when cared for by both (Parker 1985; McNamara et al. 2003; Houston et al. 2005). This prediction was supported by results presented by Royle et al. (2002), where offspring of zebra finch Taeniopygia guttata received 25\% more care (per nestling) from single females than those cared for by both parents (Royle et al. 2002). Regarding the first option, McNamara et al. (2003) compared the difference between the partial and the complete loss of a mate's contribution in the context of sexual conflict over parental care. This model predicts that when one parent reduces its parental effort, the other parent should increase its effort but should not fully compensate for the decrease in the other parent's contribution to avoid being constantly exploited. As a result of this conflict, the two parents are continuously "negotiating" with each other during each breeding event over the level of care each provides (McNamara et al. 1999; Schwagmeyer et al. 2002; Székely 2014) because such negotiations reduce the danger that one parent will be exploited by the other.
It is important to note that studies addressing overcompensation have mostly been conducted in captive conditions where food is not limited and study species are mostly restricted to altricial birds. One of the first studies to document overcompensation in natural conditions on passerines is one that compared the parental effort of rock sparrows, Petronia petronia, between three groups: pairs that cooperated, nests with only female care, and nests with only male care (Griggio and Pilastro 2007). During the period of biparental care, females provided more care than males but there were no differences in the feeding rate among the three groups. The effect of mate absence modified this scenario as both sexes adjusted their care, with females overcompensating for male absence and males only partially compensating for the loss of the female. Moreover, the mean survival rate was lower in the male-only broods (Griggio and Pilastro 2007). Theoretical models on sexual conflict over parental care suggest that, in a negotiation process, parents are expected to retain mates and cooperate since it would be beneficial (McNamara et al. 1999). The results revealed an unexpectedly plastic response of parental care after reduction of mate effort. These findings are consistent with theoretical models of parental investment that take sexual conflict into account (Parker 1985; McNamara et al. 2003), although males and females differed in their strategy for compensation. A removal or a handicapping experiment would be necessary to exclude the confounding effects of betweenindividual differences in quality among sexes of each group. The evidence is contradictory in other species with some studies reporting partial compensation (Wright and Cuthill 1989; Smiseth and Amundsen 2000; Smiseth et al. 2005), and others reporting no compensation (Slagsvold and Lifjeld 1990) or full compensation (Wright and Cuthill 1989; Wright and Cuthill 1990; Leniowski and Wegrzyn 2018). Additionally, the responses could be more pronounced in birds during an early stage of chick development where female absence would lead to brood failure, as chicks still need female brooding as they have not fully developed self-endothermy.

To test if male and female parents adjust their level of investment relative to their partner's contribution in the rock sparrow, we compared the behavioral responses of each sex to an experimental mate removal. Pair member interactions have been demonstrated to be important in the process of brood desertion (Griggio and Venuto 2007). Moreover, we also know that when an individual is going to desert it spends progressively less time at the nest (Griggio et al. 2005). Here, we experimentally mimic the starting phase of the desertion process. In the rock sparrow, both sexes may desert the brood, thus there is a strong sexual conflict over parental care (Pilastro et al. 2001; Griggio et al. 2005; Griggio and Pilastro 2007). To test for a sex difference in the response to mate removal and how fast the reaction in species with brood desertion by both sexes is, we removed the female parent in one experimental group and the male in the second experimental 
group. Following Smiseth et al. (2005), we used a repeated measures design to test how individuals respond to the experimentally induced reductions in care provided by a mate who had previously helped. Although we expected to observe partial compensation by each parent, we predicted that males (the sex less involved in offspring care because females are brooding the nestlings (Griggio and Pilastro 2007), may show the greatest response as they would have more scope for increasing effort. In addition, the absence of a brooding patch in males would reinforce this response. Finally, we examined potential effects on parental fitness caused by the effect of mate removal on nestling condition.

\section{Material and methods}

\section{Study species and data collection}

The rock sparrow shows a highly variable system of biparental care in which males either: (i) cooperate with females during the first week after hatching and then gradually decrease their food provisioning rate as the nestlings age; (ii) desert the brood (approximately $20 \%$ of the males); or (iii) care exclusively for the nestlings following female desertion, where the female lays a second clutch in another nest (ca. 10\% of the females that successfully raised their first brood: Pilastro et al. 2001; Griggio 2015).

The study was conducted during the spring of 2016 and 2017 in a deciduous forest of Quercus pyrenaica in central Spain where 570 nest boxes have been erected (see Lambrechts et al. 2010 for measurements and placement of nest boxes). Nest boxes occupied by rock sparrows were checked every 4 days from the early stages of nest construction to fledging. Egg laying in the rock sparrow population under study typically begins in late May with clutches ranging from 3 to 7 eggs. Chicks are fed on insects (mainly grasshoppers and caterpillars). Chicks usually fledge at the age of 18 days. Laying dates, hatching dates, clutch sizes, and reproductive performance (hatching success, breeding success) are recorded and nestlings are measured and weighed on day 14 every year (Cantarero et al. 2017). Mass was recorded with a Pesola spring balance (accuracy of $0.1 \mathrm{~g}$ ) and tarsus length was measured with a digital caliper to the nearest $0.01 \mathrm{~mm}$. Wing length was measured with a stopped ruler to the nearest $\mathrm{mm}$. A small sample of blood from the brachial vein (10$20 \mathrm{ml}$ ) was taken and stored on Flinders Technology Associates reagent loaded cards (Whatman Bioscience, Florham Park, NJ, USA) until needed for molecular sexing.

\section{Experimental mate removal}

The experiment was carried out in 36 breeding pairs (18 pairs in 2016 and 18 pairs in 2017). To induce a reduction in care provided by an individual, one random member of the pair was captured in their nest boxes with traps while provisioning nestlings of 7 days (Fig. 1) and retained in an opaque wooden cage for a period of $1 \mathrm{~h}$ before being released. The experimental mate removal was admittedly a mild simulation of natural reductions in mate effort, as enforcing drastic effects would have possible repercussions on desertion (Griggio et al. 2005). Nevertheless, subsequent filming allowed us to verify that the removed individual was absent from the nest for at least $4 \mathrm{~h}$ (no captured individuals were seen feeding the chicks in videos recorded shortly after the experimental removal). We captured the first individual that approached the nest box. All removed individuals were observed feeding offspring the day after the experimental removal. In total, we captured 24 females (hereafter, "female removal") and 12 males (hereafter, "male removal"). Captured birds were ringed if necessary or identified, weighed, and measured following the same protocol as nestlings. As adults and chicks are color-ringed yearly in this population, most of the birds were easily identified in the video recordings. Nevertheless, individuals were painted on the tail with permanent nontoxic water-based red paint markers (GALIAN COGASA, Murcia, Spain) to confirm sex assignment. All captured adult individuals were also photographed to analyze their ornamentation. We photographed the breast yellow patch with a ruler beside for reference. All digital photos were later analyzed with Adobe Photoshop CS4 (version 11.0) to estimate surfaces following Moreno et al. (2014). The other parent was captured 3 days after the experiment was carried out and measured in the same way as its mate.

\section{Video recordings}

Nest boxes were filmed 6, 7, and 8 days after the day of hatching of the young (hatching day $=$ day 1 ) recording periods of $180 \mathrm{~min}$ per day $(193.3 \pm \mathrm{SD} 54.3 \mathrm{~min}, N=108)$ with a digital video camera placed on the roof outside the nest box. We recorded three feeding events by one or two mates for each nest box (Fig. 1): pre-mate removal (hereafter, "day -1 "), the day of the mate removal right after the capture (hereafter, "day 0 ") and post-mate removal (hereafter, "day 1"). All films were recorded from 08:00 to 14:00 $\mathrm{h}$ and no differences between experimental groups with respect to hour of filming were found (day $-1: U=114.0, P=0.516$; day $0: U=129.5$, $P=0.768$; day $1: U=107, P=0.368$ ). To minimize observer bias, blinded methods were used when all behavioral data were recorded and/or analyzed. For each filming session, we noted the time elapsed until the first visit of each parent (time delay) and we also obtained hourly provisioning rates by males and females. The quickness in returning to the nest may be a valuable indicator of how much effort birds are willing to expend to care for their offspring. Additionally, we calculated the ratio of parental provisioning as the 
Fig. 1 Scheme showing the experimental procedure of the study

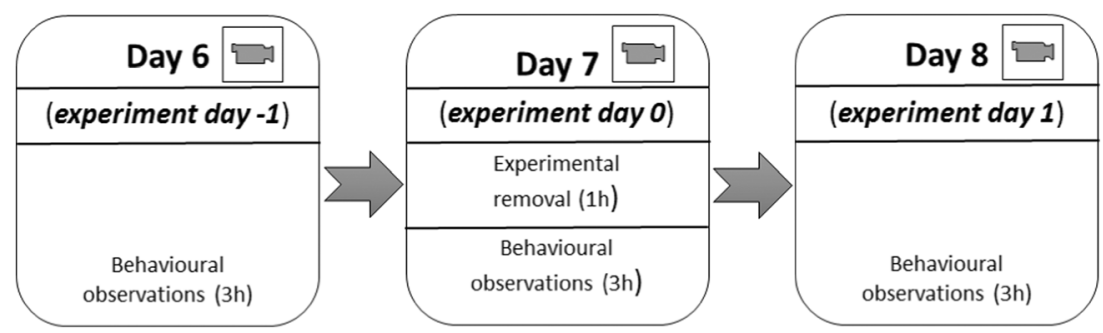

proportion of the female to male provisioning rate. To verify possible repercussions of capture and manipulation on the behavior of the pairs, we compared the behavior of these 36 pairs with that of 19 pairs from a previous year (2013: AC et al. unpublished data).

\section{Molecular sexing}

The sex of nestlings was determined from blood using a standard extraction protocol that digests the cards where the blood was fixed. After that, the CHD (chromo-helicase DNA binding protein) sequence present in both $\mathrm{W}$ and $\mathrm{Z}$ avian chromosomes were amplified throughout polymerase chain reactions (PCR) using the primers $\mathrm{P} 2$ and P8 (Ellegren 1996; Griffiths and Tiwari 1996). We identified females as showing two gene copies (W- and Z-linked genes) and males displayed a single copy (Z-linked gene) as described in Griffiths et al. (1998).

\section{Statistical analyses}

We first conducted paired $t$ tests including all 36 broods testing sex differences in parental care before our mate removal experiment (day -1). Next, we examined differences in breeding variables by using ANOVA tests (STATISTICA package) with treatment as the explanatory factor (as they were normally distributed, Kolmogorov-Smirnov, $P>0.20$ ). Following Griggio and Hoi (2010), the individual body condition was calculated by dividing body mass by (tarsus length) ${ }^{3}$. Yellow patch size and body condition were also normally distributed and ANOVA tests were performed to analyze differences in these traits between adults from the two treatments. The potential effects of treatment on nestling mass near fledging and morphometric measurements were analyzed using Generalized Linear Models with treatment as the explanatory factor, and year, hatching date and brood size as continuous predictors.

Since the captured individual did not feed the chicks (and therefore there is no latency time) during filming on the day of the experimental removal (day 0 ), the provisioning rates of the male and the female between day -1 and day 0 and/or day 0 and day 1 were compared using simple ANOVA models. We then examined the extent of behavioral adjustments (provisioning rates and latency before first visit) for each sex using repeated measures ANCOVAs in which the provisioning rates before (day -1 ) and after (day 1) mate removal were the dependent variables (within-subject factors) with treatment as the explanatory factor and before/after mate removal as a repeated-measures effect. Year and hour of filming were included as covariates. Repeated measures ANCOVAs examine individual changes in behavior to test the effect of mate removal. We conducted separate ANCOVAs for female and male behaviors. The same model was performed by using the ratio of parental provisioning before or after mate removal as dependent variables.

\section{Data availability}

The data that support the findings of this study are available from the corresponding author, $\mathrm{AC}$, upon reasonable request.

\section{Results}

The two experimental groups were similar with respect to hatching date, clutch size, sex ratio, or brood size (Table 1, all $P>0.30$ ). Neither male nor female yellow patch size and body condition differed between treatments (Table 1). Furthermore, there were no significant differences in the tarsus length $\left(F_{1,36}=1.71, P=0.202\right)$ or average body condition (a fitness-correlated trait) between broods $\left(F_{1,36}=0.21, P=\right.$ $0.654)$. The body condition of the nestlings was negatively associated with hatching date $\left(F_{1,1}=6.79, P=0.015\right)$.

There were strong differences among sexes before our experimental removal of the mate (day - 1). Female provisioning rates were higher than male provisioning rates (paired $t$ test: $t=3.96, \mathrm{df}=69, P<0.001$ ), and females also showed a shorter time from disturbance to the first visit to the nest $(t=-$ $2.52, \mathrm{df}=69, P<0.014)$. Females provisioned the offspring 1.5 times more frequently (females, $4.81 \pm \mathrm{SD} 1.65$ feeds $/ \mathrm{h}$; males, $3.25 \pm$ SD 1.87 feeds/h) and appeared at the nest after disturbance 1.9 times faster than did males (females, $10.85 \pm$ SD $9.25 \mathrm{~min}$; males, $20.40 \pm$ SD $20.43 \mathrm{~min}$ ). However, there was no significant difference in provisioning rates $(t=0.88$, $\mathrm{df}=66, P=0.38)$ or the time of return to the nest $(t=-1.07$, $\mathrm{df}=66, P=0.29$ ) between males and females after the experimental removal of the mate (day 1). Interestingly, while females showed similar provisioning rates compared to a 
Table 1 Average ( \pm SE) values for breeding variables and adults measurements of nests included in the two treatments and results of ANOVA tests

\begin{tabular}{lrrrl}
\hline & Female removal & Male removal & Statistic & $p$ \\
\hline Hatching date & $76.62 \pm 8.58$ & $77.25 \pm 5.72$ & $F_{1}=0.052$ & 0.821 \\
Clutch size & $5.29 \pm 0.62$ & $5.50 \pm 0.67$ & $F_{1}=0.846$ & 0.364 \\
Sex ratio & $0.46 \pm 0.30$ & $0.53 \pm 0.31$ & $F_{1}=0.064$ & 0.551 \\
Brood size 13 days & $3.62 \pm 1.93$ & $3.08 \pm 1.62$ & $F_{1}=0.697$ & 0.409 \\
Female yellow patch $\left(\mathrm{cm}^{2}\right)$ & $0.26 \pm 0.14$ & $0.28 \pm 0.13$ & $F_{1}=0.065$ & 0.801 \\
Female body condition & $49.44 \pm 5.22$ & $48.10 \pm 4.47$ & $F_{1}=0.464$ & 0.501 \\
Male yellow patch $\left(\mathrm{cm}^{2}\right)$ & $0.24 \pm 0.09$ & $0.31 \pm 0.25$ & $F_{1}=1.264$ & 0.264 \\
Male body condition & $47.05 \pm 5.15$ & $47.49 \pm 4.87$ & $F_{1}=0.052$ & 0.821 \\
\hline
\end{tabular}

previous year (2013: AC et al. unpublished data), males fed the nestlings more times per hour (females, $4.75 \pm 2.72 \mathrm{vs}$ $4.76 \pm 2.98 \mathrm{feeds} / \mathrm{h}$ in year 2013; $t=-0.007, \mathrm{df}=50, P=$ 0.993 ; males, $5.01 \pm 1.99$ vs $3.33 \pm 2.28$ feeds $/ \mathrm{h}$ in year 2013; $t=-2.33, \mathrm{df}=46, P=0.033$ ).

We found sex-specific differences to the experimental removal. Females did not significantly change parental care in response to the removal of the male (Fig. 2a; interaction treatment with repeated measures, day -1 vs day $1 ; F_{1,31}=0.898$, $P=0.351)$. On the contrary, males increased their provisioning rate in response to female removal. While males showed similar provisioning rates before and after they were captured, they showed a marked increase in provisioning rates when the female was absent (Fig. 2b; interaction treatment with repeated measures, day -1 vs day $1 ; F_{1,31}=10.84, P=0.003$ ). Similar results were found when using the ratio of parental provisioning as dependent variables (interaction treatment with repeated measures, day -1 vs day $1 ; F_{1,31}=4.88, P=$ $0.037)$. No effect of year or hour on parental provisioning was found (all $P>0.14$ ). However, neither males nor females showed significant differences in provisioning rates during the day of the experimental mate removal (comparisons day -1 vs day 0 and day 0 vs day 1 ; all $P>0.15$ ). Thus, only males seem to adjust the provisioning rates in response to mate removal.

We did not find differences between sexes in the time it took to return to the nest when the male was experimentally removed (Table 2). On the contrary, females took longer to return to the nest as a response to its capture and males seemed to be able to respond to the female's absence by returning to the nest faster from day 0 to day 1 (Table 2).

\section{Discussion}

Our aim in this study was to test sexual differences in parental care in response to an experimental mate removal during an early stage of chick development. We found that only males behaved according to a prediction of compensatory adjustment, as they allocated more care to the offspring and returned faster to the nest after female removal. There were no detrimental effects on offspring growth of male or female removal. Below, we discuss the implications of our results for the general understanding of the resolution of sexual conflict over parental care.

Rock sparrow males adjusted their provisioning rate after mate removal, whereas females did not. Male provisioning rates were even higher than in the previous year. Thus, only the sex less involved in offspring care adjusted their behavior facultatively in response to mate removal. These results are consistent with the results found by Møller (2000) in a
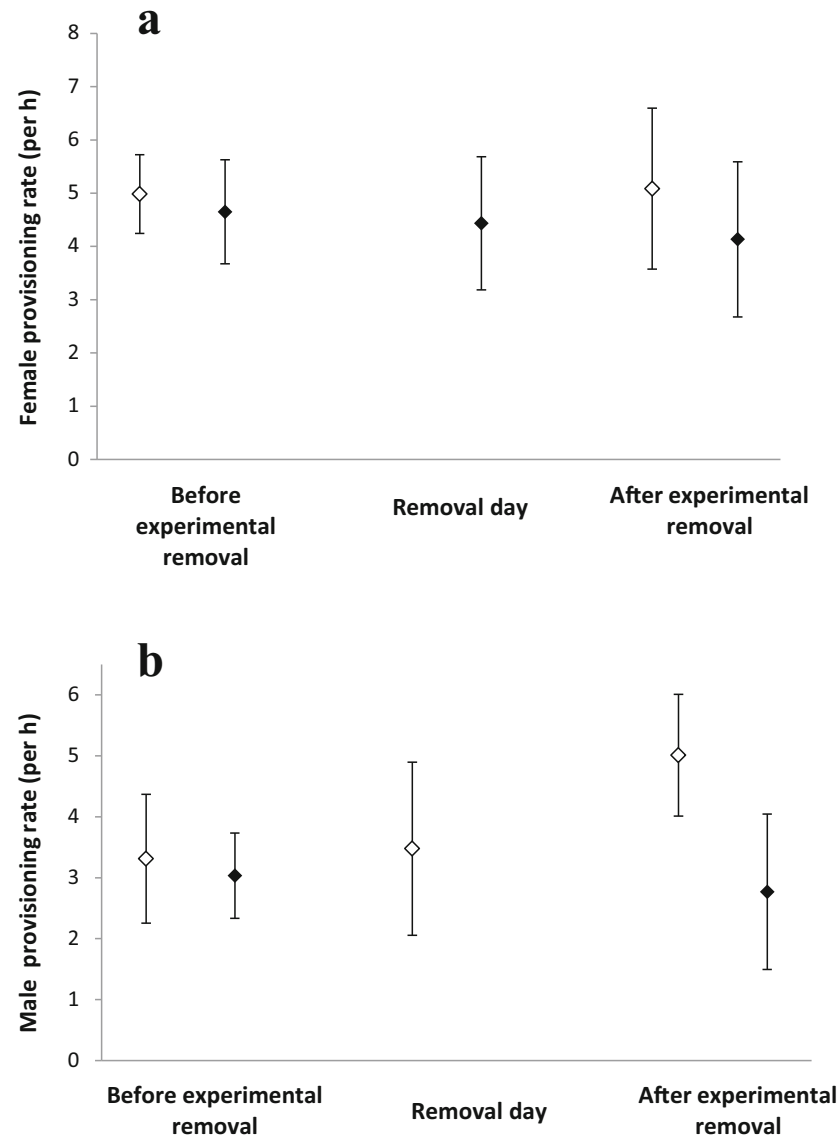

Fig. 2 Variation in provisioning rates of rock sparrows during the early nestling phase, comparing female $(\diamond)$ and male removal groups $(\diamond)$. Means $\pm \mathrm{SE}$ of $\mathbf{a}$ female and $\mathbf{b}$ male provisioning rates before, during, and after experimental removal are presented 
Table 2 Differences (means \pm $\mathrm{SE}$ ) in the time of return to the nest of the first parental feeding between treatments. Data followed by the same symbol (*) differ $(P<0.05)$

\begin{tabular}{lrrr}
\hline Latency time (minutes) & \multicolumn{1}{c}{ Day -1} & \multicolumn{1}{c}{ Day 0 } & \multicolumn{1}{c}{ Day 1 } \\
\hline Female removal & & & \\
$\quad$ Female & $9.5 \pm 9.03^{*}$ & $0.0 \pm 0.0$ & $18.62 \pm 18.25^{*}$ \\
$\quad$ Male & $29.57 \pm 58.12$ & $45.27 \pm 43.08^{*}$ & $14.4 \pm 13.97^{*}$ \\
Male removal & & & \\
$\quad$ Female & $11.65 \pm 7.65$ & $27.38 \pm 41.98$ & $14.0 \pm 18.98$ \\
$\quad$ Male & $20.88 \pm 21.0$ & $0.0 \pm 0.0$ & $34.02 \pm 43.98$ \\
\hline
\end{tabular}

previous comparative study on birds, as well as a series of experimental studies dealing with the effect of mate removal on parental care behavior in dung beetles (Hunt and Simmons 2002; Smiseth and Moore 2004; Smiseth et al. 2005; Suzuki and Nagano 2009) and poison frogs, Allobates femoralis (Ringler et al. 2015). Theoretical models of sexual conflict over parental care give increasing attention to "negotiation" models, which assume that members of a pair do not make independent decisions but negotiate to modify their effort in direct response to the prior effort of their mate (Houston and McNamara 1999; Houston et al. 2005). Moreover, the different responses may involve a number of different interactions between pair members (Hunt and Simmons 2002; Griggio et al. 2005; Griggio and Venuto 2007). Our results suggest the payoffs for caring may be different for the two sexes and the responses could be different depending on the stage of offspring development.

First, we found no effects of the experimental male removal on female provisioning frequency which suggests that female rock sparrows were working near their maximum capacity. This seems different to the results found by Griggio et al. (2005) in the same species, who found that both males and females increased their feeding effort when deserted by their mate. However, that study was performed during the late stage of chick development and one of the parents had already deserted the brood. A different version of this scenario could be applied to the stage when chicks still require care by the female and are still being fed by both parents. Age-related differences in paternal care are greatest during the first few days after hatching when nestlings have to be brooded by females. Development of nestling endothermy causes changes in parental behavior, as nestlings no longer depend on being brooded (Leniowski and Wegrzyn 2018). In fact, some studies have shown that endothermic nestlings required more intensive feeding (Leniowski and Wegrzyn 2018), and therefore, females may devote less time to brooding to increase the feeding effort. Moreover, there is some evidence in another species that responses to variation in brood demand may be precluded as the female effort is energetically constrained (Moreno et al. 1995, 1997). In contrast, male parents showed facultative adjustments in parental behavior. The increased male effort in response to female removal suggests that males in a nonexperimental situation did not feed the nestlings at their maximum possible intensity. Given that each parent has limited resources to invest in any given reproduction event, individuals are expected to reduce current investment to save for future breeding efforts and to try to force its mate to invest more, generating sexual conflict over parental investment (McNamara et al. 2003). In most passerines, only females develop brood patches, so female activities (incubation and brooding) are more valuable before chicks attain full homeothermy (Székely et al. 1999). Our experiment was carried out during a critical stage of chick development, where the chicks were still dependent on the female as the males could not take care of the offspring by themselves. Moreover, we must note that we are mimicking the starting phase of a long desertion process. By increasing the parental effort as a response to female removal, males could be showing to their mates their willingness to invest in the current brood and thus convince females to stay, as their abandonment would lead to brood failure. Furthermore, we assume that quickness in returning to the nest is a valuable indicator that males perceived the absence of their mate during the experimental removal and were able to respond to it consistently.

Most models of sexual conflict over parental care assume that in a process of decision-making, the female makes her choice on the basis of her mate decision (Barta et al. 2002; McNamara et al. 2003). Some authors have stated that simple observation of the behavior of each parent and estimates of their subsequent reproductive success are not enough to control for the confounding effects between such behavior and individual quality (Székely and Cuthill 1999; Székely et al. 1999). Thus, the observed difference in the parental resources allocated among sexes in rock sparrows after mate removal could derive from different sexual strategies of reproductive investment before removal and to their consequences for longterm survival and re-mated breeding attempts (Pilastro et al. 2001; Tavecchia et al. 2002). Further experimental work is now needed to understand the sex-specific costs and benefits of decision-making in parental behavior. We found that females were more involved in feeding offspring when both parents cared jointly. This is consistent with previous studies on this species (Griggio et al. 2005; Griggio and Pilastro 2007). However, prior studies on biparental care in birds have 
reported similar food provisioning rates among sexes (Sanz et al. 2000; Magrath et al. 2007; Adler and Ritchison 2011; Cantarero et al. 2014, 2016; Serrano-Davies and Sanz 2017). Nevertheless, there was no significant difference in provisioning rates between males and females after the experimental removal of the mate which could explain the absence of detrimental effects among treatments on offspring measurements. The evidence for other species supports our findings, as changes in parental behavior did not influence nestling growth (Székely and Cuthill 1999; Székely et al. 1999).

In summary, our study partially supports predictions of theoretical models on sexual conflict over parental care, although there was a different compensation strategy used by males and females. Moreover, our results together with previous studies seem to indicate that compensation strategies are influenced by the growth stage of the young. A fundamental question concerns the rules that parents use when responding to their partner's effort (McNamara et al. 2003). One possibility is that members of a pair do not make independent decisions, but negotiate to modify their effort on the basis of its partner's effort.

Acknowledgments We thank the two reviewers whose suggestions helped improve and clarify this manuscript. We thank Alexandra Nance for the English review.

Funding Open access funding provided by University of Turku (UTU) including Turku University Central Hospital. This study was financed by project CGL2017-83843-C2-1 to JM from Spanish Ministerio de Economía y Competitividad (MINECO). AC is supported by a postdoctoral fellowship from Fundación Ramón Areces. MP was supported by an FPI grant from MINECO. This work was done while the first author was visiting the University of Padova supported by the Program "José Castillejo" (grant CAS18/00139).

\section{Compliance with ethical standards}

Conflict of interest The authors declare that they have no conflict of interest.

Ethical approval All applicable international, national, and/or institutional guidelines for the care and use of animals were followed. Field researchers were officially licensed for animal manipulation following current EU regulations on animal manipulation (authorization types D and $\mathrm{C}$ by regional authorities, Reference CAPT-T-0122-15). Permissions for handling birds were provided by "Consejería de Medio Ambiente de Castilla y León"| (regional government with attributions on the capture of wild birds, protocol number EP/SG/706/2016). The study was ethically approved by the Ethical Committee of "Consejo Superior de Investigaciones Científicas" (CSIC) and by the regional administration competent in matters related to animal protection in research according to Royal Decree 53/2013 (Dirección General de Producción Agropecuaria y Desarrollo Rural, Junta de Castilla y León).

Open Access This article is distributed under the terms of the Creative Commons Attribution 4.0 International License (http:// creativecommons.org/licenses/by/4.0/), which permits unrestricted use, distribution, and reproduction in any medium, provided you give appropriate credit to the original author(s) and the source, provide a link to the Creative Commons license, and indicate if changes were made.

\section{References}

Adler J, Ritchison G (2011) Provisioning behavior of male and female grasshopper sparrows. Wilson J Ornithol 123:515-520

Barta Z, Houston AI, McNamara JM, Székely T (2002) Sexual conflict about parental care: the role of reserves. Am Nat 159:687-705

Birkhead TR (1999) Book review of The Evolution of Avian Breeding Systems by Ligon JD. Heredity 83:101

Cantarero A, López-Arrabé J, Palma A, Redondo AJ, Moreno J (2014) Males respond to female begging signals of need: a handicapping experiment in the pied flycatcher Ficedula hypoleuca. Anim Behav 94:167-173

Cantarero A, López-Arrabé J, Plaza M, Saavedra-Garcés I, Moreno J (2016) Males feed their mates more and take more risks for nestlings with larger female-built nests: an experimental study in the nuthatch Sitta europaea. Behav Ecol Sociobiol 70:1141-1150

Cantarero A, López-Arrabé J, Palma A, Moreno J (2017) Oxidative status in nestlings shows different associations with parental carotenoidbased plumage ornaments depending on parental sex and year: a study of rock sparrows Petronia petronia. Ethol Ecol Evol 29: $521-541$

Clutton-Brock TH (1991) The evolution of parental care. Princeton University Press, Princeton

Cockburn A (2006) Prevalence of different modes of parental care in birds. Proc R Soc Lond B 273:1375-1383

Ellegren H (1996) First gene on the avian W chromosome (CHD) provides a tag for universal sexing of non-ratite birds. Proc R Soc Lond B 263:1635-1641

Griffiths R, Tiwari B (1996) Avian ghd genes and their use in methods for sex identification in birds. International patent publication no. WO9639505, published 12 December 1996. Isis Innovation, Oxford

Griffiths R, Double MC, Orr K, Dawson RJ (1998) A DNA test to sex most birds. Mol Ecol 7:1071-1075

Griggio M (2015) An experimental test on time constraint and sexual conflict over parental care. Ecol Evol 5:3622-3627

Griggio M, Hoi H (2010) Only females in poor condition display a clear preference and prefer males with an average badge. BMC Evol Biol 10:261

Griggio M, Pilastro A (2007) Sexual conflict over parental care in a species with female and male brood desertion. Anim Behav 74: 779-785

Griggio M, Venuto G (2007) The relationship between mate guarding and brood desertion in the rock sparrow Petronia petronia. Ethol Ecol Evol 19:175-182

Griggio M, Matessi G, Pilastro A (2005) Should I stay or should I go? Female brood desertion and male counterstrategy in rock sparrows. Behav Ecol 16:435-441

Harrison F, Barta Z, Cuthill I, Székely T (2009) How is sexual conflict over parental care resolved? A meta-analysis. J Evol Biol 22:1800 1812

Houston AI, McNamara JM (1999) Models of adaptive behaviour. Cambridge University Press, Cambridge

Houston AI, Székely T, McNamara JM (2005) Conflict between parents over care. Trends Ecol Evol 20:33-38

Hunt J, Simmons LW (2002) Behavioural dynamics of biparental care in the dung beetle Onthophagus taurus. Anim Behav 64:65-75

Jönsson KI, Tuomi J, Järemo J (1998) Pre- and postbreeding costs of parental investment. Oikos 83:424-431

Lack D (1968) Ecological adaptations for breeding in birds. Methuen, New York

Lambrechts M, Adriaensen F, Ardia DR et al (2010) The design of artificial nestboxes for the study of secondary hole-nesting birds: a review of methodological inconsistencies and potential biases. Acta Ornithol 45:1-26 
Lendvai ÁZ, Barta Z, Chastel O (2009) Conflict over parental care in house sparrows: do females use a negotiation rule? Behav Ecol 20: $651-656$

Leniowski K, Wegrzyn E (2018) The ecological consequences of solitary breeding in a species with bi-parental care. Ornis Fenn 95:128-136

Leniowski K, Wegrzyn E (2018) Synchronisation of parental behaviours reduces the risk of nest predation in a socially monogamous passerine bird. Sci Rep 8:7385

Magrath M, Janson J, Komdeur J, Elgar M, Mulder R (2007) Provisioning adjustments by male and female fairy martins to short-term manipulations of brood size. Behaviour 144:1119-1132

McNamara JM, Gasson CE, Houston AI (1999) Incorporating rules for responding into evolutionary games. Nature 401:368-371

McNamara JM, Houston AI, Barta Z, Osorno J-L (2003) Should young ever be better off with one parent than with two? Behav Ecol 14: $301-310$

Møller AP (2000) Male parental care, female reproductive success, and extrapair paternity. Behav Ecol 11:161-168

Moreno J, Cowie RJ, Sanz JJ, Roberts SRW (1995) Differential response by males and females to brood manipulations in the pied flycatcher: energy expenditure and nestling diet. J Anim Ecol 64:721-732

Moreno J, Potti J, Merino S (1997) Parental energy expenditure and offspring size in the pied flycatcher Ficedula hypoleuca. Oikos 79: 559-567

Moreno J, Gil D, Cantarero A, López-Arrabé J (2014) Extent of a white plumage patch covaries with testosterone levels in female pied flycatchers Ficedula hypoleuca. J Ornithol 155:639-648

Osorno JL, Székely T (2004) Sexual conflict and parental care in magnificent frigatebirds: full compensation by deserted females. Anim Behav 68:337-342

Parker GA (1985) Models of parent-offspring conflict. V. Effects of the behaviour of the two parents. Anim Behav 33:519-533

Persson O, Öhrström P (1989) A new avian mating system: ambisexual polygamy in the penduline tit Remiz pendulinus. Ornis Scand 20: 105-111

Pierce EP, Oring LW, Røskaft E, Lifjeld JT (2010) Why don't female purple sandpipers perform brood care? A removal experiment. Behav Ecol 21:275-283

Pilakouta N, Hanlon EJH, Smiseth PT (2018) Biparental care is more than the sum of its parts: experimental evidence for synergistic effects on offspring fitness. Proc R Soc B 285:20180875

Pilastro A, Biddau L, Marin G, Mingozzi T (2001) Female brood desertion increases with number of available mates in the rock sparrow. $\mathrm{J}$ Avian Biol 32:68-72

Pilastro A, Griggio M, Matessi G (2003) Male rock sparrows adjust their breeding strategy according to female ornamentation: parental or mating investment? Anim Behav 66:265-271

Ringler E, Pašukonis A, Fitch WT, Huber L, Ringler M, Hödl W (2015) Flexible compensation of uniparental care: female poison frogs take over when males disappear. Behav Ecol 26:1219-1225

Royle NJ, Hartley IR, Parker GA (2002) Sexual conflict reduces offspring fitness in zebra finches. Nature 416:733-736

Santos ESA, Nakagawa S (2012) The costs of parental care: a metaanalysis of the trade-off between parental effort and survival in birds. J Evol Biol 25:1911-1917
Sanz JJ, Kranenbarg S, Tinbergen JM (2000) Differential response by males and females to manipulation of partner contribution in the great tit (Parus major). J Anim Ecol 69:74-84

Schwagmeyer PL, Mock DW, Parker GA (2002) Biparental care in house sparrows: negotiation or sealed bid? Behav Evol 13:713-721

Serrano-Davies E, Sanz JJ (2017) Habitat structure modulates nestling diet composition and fitness of blue tits Cyanistes caeruleus in the Mediterranean region. Bird Study 64:295-305

Slagsvold T, Lifjeld JT (1990) Influence of male and female quality on clutch size in tits (Parus spp.). Ecology 71:1258-1266

Smiseth PT, Amundsen T (2000) Does female plumage coloration signal parental quality? A male removal experiment with the bluethroat (Luscinia s. svecica). Behav Ecol Sociobiol 47:205-212

Smiseth PT, Moore AJ (2004) Behavioral dynamics between caring males and females in a beetle with facultative biparental care. Behav Ecol 15:621-628

Smiseth PT, Dawson C, Varley E, Moore AJ (2005) How do caring parents respond to mate loss? Differential response by males and females. Anim Behav 69:551-559

Suzuki S, Nagano M (2009) To compensate or not? Caring parents respond differentially to mate removal and mate handicapping in the burying beetle, Nicrophorus quadripunctatus. Ethology 115:1-6

Székely T (2014) Sexual conflict between parents: offspring desertion and asymmetrical parental care. Cold Spring Harb Perspect Biol 6: 19017665

Székely T, Cuthill IC (1999) Brood desertion in Kentish plover the value of parental care. Behav Ecol 10:191-197

Székely T, Webb JN, Houston AI, McNamara JM (1996) An evolutionary approach to offspring desertion in birds. In: Nolan V, Ketterson ED (eds) Current ornithology. Springer US, Boston, MA, pp 271-330

Székely T, Cuthill IC, János K (1999) Brood desertion in Kentish plover sex differences in remating opportunities. Behav Ecol 10:185-190

Szentirmai I, Székely T, Komdeur J (2007) Sexual conflict over care: antagonistic effects of clutch desertion on reproductive success of male and female penduline tits. J Evol Biol 20:1739-1744

Tavecchia G, Pradel R, Lebreton JD, Biddau L, Mingozzi T (2002) Sexbiased survival and breeding dispersal probability in a patchy population of the rock sparrow Petronia petronia. Ibis 144:E79-E87

Trivers RL (1972) Parental investment and sexual selection. In: Campbell B (ed) Sexual selection and the descent of man. Aldine, Chicago, IL, pp 136-179

Wesołowski T (2004) The origin of parental care in birds: a reassessment. Behav Ecol 15:520-523

Wright J, Cuthill I (1989) Manipulation of sex differences in parental care. Behav Ecol Sociobiol 25:171-181

Wright J, Cuthill I (1990) Biparental care: short-term manipulation of partner contribution and brood size in the starling, Sturnus vulgaris. Behav Ecol 1:116-124

Publisher's note Springer Nature remains neutral with regard to jurisdictional claims in published maps and institutional affiliations. 